Eur. J. Clin. Chem. Clin. Biochem.

Vol. 30, 1992, pp. $7-10$

(c) 1992 Walter de Gruyter \& Co. Berlin - New York

\title{
Electrophoretic Analysis of Isoforms of Glyoxalase II in Clinical Blood Samples
}

\author{
By A. C. McLellan and P. J. Thornalley ${ }^{1}$ )
}

The Glyoxalase Research Group, Department of Chemistry and Biological Chemistry, University of Essex

(Received April 22/November 11, 1991)

Summary: A non-denaturing polyacrylamide gel electrophoresis procedure is described for the analysis of isoforms of human red blood cell glyoxalase II (EC 3.1.2.6). A cathodic, continuous buffer electrophoresis system was developed, using a $60 \mathrm{~g} / 1$ polyacrylamide gel with $25 \mathrm{~g} / 1 \mathrm{~N}, \mathrm{~N}^{1}$-methylene-bis-acrylamide in $50 \mathrm{mmol} / 1$ sodium succinate buffer, $\mathrm{pH} 5.5$ and $1^{\circ} \mathrm{C}$. Staining for glyoxalase II activity involved

(a) washing the gel with $50 \mathrm{mmol} / 1 \mathrm{Tris}-\mathrm{HCl}$ buffer, $\mathrm{pH} 7.4$ and $37^{\circ} \mathrm{C}$, and

(b) incubation with developing agent $(0.5 \mathrm{~g} / 1$ 3-[4,5-dimethylthiazol-2-yl]-2,5-diphenyltetrazolium bromide, $0.1 \mathrm{~g} / 1$ 2,6-dichlorophenolindophenol, $1 \mathrm{mmol} / \mathrm{l} \mathrm{S}-D$-lactoylglutathione in $100 \mathrm{mmol} / \mathrm{l}$ Tris- $\mathrm{HCl}, \mathrm{pH} 7.4$ ).

Two activity bands were found in all human blood samples studied to date, probably reflecting the presence of two major isoforms. Optimal sample storage and preparation procedures and validation studies are described. This method is currently in use in an ongoing investigation of glyoxalase II isoforms in disease processes.

\section{Introduction}

Glyoxalase II (hydroxyacylglutathione hydrolase) ${ }^{2}$ ) catalyses the hydrolysis of S- $D$-lactoylglutathione to reduced glutathione and $D$-lactate (1).

$$
\begin{array}{ll}
\mathrm{MeCH}(\mathrm{OH}) \mathrm{CO}-\mathrm{SG} & \text { Glyoxalase II } \\
+\mathrm{H}_{2} \mathrm{O} & \begin{array}{l}
\mathrm{MeCH}(\mathrm{OH}) \mathrm{CO}_{2} \mathrm{H} \\
+\mathrm{GSH}
\end{array}
\end{array}
$$

Human red blood cell glyoxalase II is a monomeric protein of relative molecular mass $M_{\mathrm{r}} 21000$. Two forms of glyoxalase II with pI values of 8.09 and 8.40 have been resolved by chromatofocussing (2). Glyoxalase II is present in the cytosol of all cells. It is a

1) Funding organisation: The Wellcome Trust

$\left.{ }^{2}\right)$ Enzymes:

$\gamma$-Glutamyltransferase, [5-glutamyl]-peptide : amino-acid 5glutamyltransferase, EC 2.3.2.2;

Glyoxalase I, S-lactoyl-glutathione methylglyoxal-lyase [isomerising], EC 4.4.1.5;

Glyoxalase II, S-2-hydroxyacylglutathione hydrolase, EC 3.1.2.6. component of the glyoxalase system which catalyses the conversion of methylglyoxal to $D$-lactate via the intermediate S- $D$-lactoylglutathione (3).

The gene for human glyoxalase II, HAGH, has been localised to chromosome band 16p13.3. The $16 \mathrm{p} 13$ band represents about half of the short arm of chromosome 16. The genetic locus for phosphoglycolate phosphatase is also present in this band $(4-6)$. Genetic polymorphism of glyoxalase II is extremely rare, and only one phenotype (HAGH1) is usually expressed. However, a rare second form, $\mathrm{HAGH} 2$, has been found in Micronesian (7) and Japanese (8) populations. The population genetics of human glyoxalases have recently been reviewed (9).

Electrophoretic analysis of glyoxalase II phenotypes is usually performed using an anodic starch gel electrophoresis method. HAGH1 is electrophoretically "slow" and HAGH2 "fast" $(8,9)$. However, the two isoforms of distinctive isoelectric point are not resolved. Uotila (1979) resolved the isoforms of glyoxalase II by chromatofocussing (2). 
In this report, we describe a non-denaturing polyacrylamide gel electrophoresis procedure for analysis of glyoxalase II isoforms. This method is currently being used to screen of glyoxalase II isoforms in diabetic patients.

\section{Materials and Methods}

Acrylamide, $\mathrm{N}, \mathrm{N}^{1}$-methylene-bis-acrylamide and $\mathrm{N}, \mathrm{N}, \mathrm{N}^{1}, \mathrm{~N}^{1}$ tetramethyl-ethylenediamine were electrophoresis grade reagents purchased from Sigma Chem. Co., Poole, Dorset, U. K. 3-[4,5-Dimethylthiazol-2-yl]-2,5-diphenyltetrazolium bromide, 2,6-dichlorophenol-indophenol, basic fuchsin, acivicin and all other reagents were of analytical grade from Sigma. S- $D$-Lactoylglutathione was synthesised enzymatically using glyoxalase $\mathrm{I}^{2}$ ) and purified by ion exchange chromatography (10).

\section{Sample preparation}

Whole blood samples, drawn by venipuncture with sodium ethylenediaminetetra-acetate anticoagulant, were treated with 4 volumes of ice-cold distilled water. The sample was centrifuged $(9000 \mathrm{~g}, 10 \mathrm{~min})$ and an aliquot of the supernatant $(150$ $\mu \mathrm{l})$ was added to $350 \mu \mathrm{l}$ of electrophoresis sample buffer $(140$ $\mathrm{g} / \mathrm{l}$ sucrose, $0.3 \mathrm{~g} / \mathrm{l}$ basic fuchsin and $30.5 \mathrm{mmol} / 1$ succinate buffer, $\mathrm{pH} 5.5$, at $1^{\circ} \mathrm{C}$ in water - see below).

\section{Apparatus}

Polyacrylamide electrophoresis gels were cast in a Pharmacia (Pharmacia LKB Biotechnology, Uppsala, Sweden) GSC-2 casting stand. Electrophoresis was performed with a Pharmacia GE 2/4 vertical electrophoresis system with a Pharmacia ECPS $3000 / 150$ power supply.

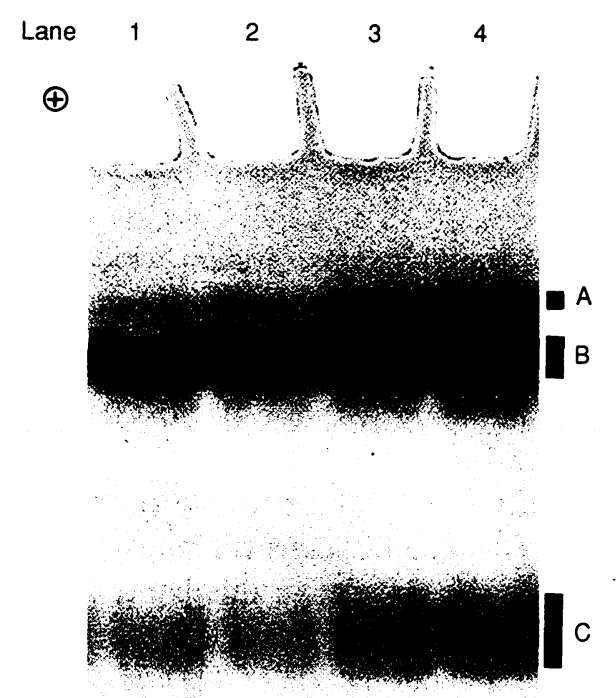

$\Theta$

Fig. 1. Non-denaturing polyacrylamide gel electrophoresis of human red blood cell glyoxalase II

Electrophoresis: The gel was prepared, electrophoresed and stained as described in the Materials and Methods section.

Lanes 1 and 2 are replicates from washed red blood cells; lanes 3 and 4 are replicates from whole blood samples.

Assignment:
A. glyoxalase II positive stain (isoform S),
B. glyoxalase II positive stain (isoform F),
C. haemoglobin band.

\section{Polyacrylamide gel electrophoresis}

Non-denaturing polyacrylamide electrophoresis was performed on a vertical cathodic continuous polyacrylamide gel (140 $\times 180 \times 1.5 \mathrm{~mm}$ ). The gel was prepared with a total concentration of $60 \mathrm{~g} / \mathrm{l}$ acrylamide and a concentration of $26 \mathrm{~g} / \mathrm{l} \mathrm{N}, \mathrm{N}^{\prime}$ methylene-bis-acrylamide in $50 \mathrm{mmol} / \mathrm{l}$ succinic acid/sodium succinate, $\mathrm{pH} 5.5$, with $3.1 \mathrm{mmol} / \mathrm{l}$ ammonium persulphate and $0.46 \mathrm{~g} / \mathrm{l} \mathrm{N}, \mathrm{N}, \mathrm{N}^{1}, \mathrm{~N}^{1}$-tetramethylethylenediamine. Electrophoresis was performed in an electrode buffer consisting of $50 \mathrm{mmol} / \mathrm{l}$ succinate buffer, $\mathrm{pH} 5.5$, at $1^{\circ} \mathrm{C}$.

The gels were pre-electrophoresed at $50 \mathrm{~V}$ for $15 \mathrm{~min}$. The protein sample $(30 \mu \mathrm{l})$ was absorbed onto the gel by applying a constant voltage of $50 \mathrm{~V}$ for $30 \mathrm{~min}$. The electrophoresis was continued for a further 6 hours at a constant of $200 \mathrm{~V}$.

\section{Staining for glyoxalase II activity}

After electrophoresis the gel was washed with $100 \mathrm{mmol} / 1$ Tris$\mathrm{HCl}$ buffer, $\mathrm{pH} 7.4$, at $37^{\circ} \mathrm{C}$. It was then incubated in developing reagent $(0.5 \mathrm{~g} / 1$ 3-[4,5-dimethylthiazol-2-yl]-2,5-diphenyltetrazolium bromide, $0.1 \mathrm{~g} / 1$ 2,6-dichlorophenolindophenol, $1 \mathrm{mmol} / \mathrm{l} \mathrm{S}$ - $D$-lactoylglutathione in $100 \mathrm{mmol} / \mathrm{l}$ Tris- $\mathrm{HCl}, \mathrm{pH}$ 7.4) at $37^{\circ} \mathrm{C}$ until the dark purple/blue bands associated with glyoxalase II activity became clearly discernable. The gel was fixed by immersion in $1.22 \mathrm{~mol} / \mathrm{l}$ acetic acid in distilled water.

\section{Results and Discussion}

Glyoxalase II activity is present in the cytosol of human blood cells: platelets, leukocytes and red blood cells $(11-13)$. The glyoxalase II activity in whole blood lysates mainly ( $>99 \%$ ) originates from lysed red blood cells.

Non-denaturing polyacrylamide gel electrophoresis of whole blood cell lysate, stained for activity of glyoxalase II is shown in figure 1. There is a red band present in the gel before staining, associated with haemoglobin. Bands of glyoxalase II activity stain appeared between the anode and the haemoglobin and during staining with the developing agent. One band, the one furthest from the anode with the greater electrophoretic mobility (isoform F), was consistently stained more intensely than the other band (isoform $S)$. The development of these bands required the presence of S- $D$-lactoylglutathione, 3-[4,5-dimethylthiazol-2-yl]-2,5-diphenyltetrazolium bromide and 2,6dichlorophenolindophenol. The same bands also appeared when other substrates of glyoxalase II were substituted for S- $D$-lactoylglutathione: S-glycolylglutathione, $\mathrm{S}-L$-glyceroylglutathione and $\mathrm{S}-D$-mandelylglutathione were all tried and proved positive (data not shown).

To bands of glyoxalase II activity were resolved in all human blood samples studied and samples of isolated red blood cells. Incubation of protein samples with the $\gamma$-glutamyltransferase $\left.{ }^{2}\right)$ inhibitor, acivicin (200 $\mu \mathrm{mol} / \mathrm{l})$, did not change the glyoxalase activity pattern or its intensity. 
Optimum blood sample processing for electrophoretic analysis of glyoxalase II isoforms was found for whole blood samples diluted with electrophoresis buffer immediately prior to electrophoresis, as described in the Materials and Methods section. Similar results were also obtained with washed red blood cells (see fig. 1). Validation studies on blood sample storage temperature were performed over a 6 week period, storing blood samples at $+4,-20$ and $-196^{\circ} \mathrm{C}$. Only storage of samples at $-196^{\circ} \mathrm{C}$ preserved fully the activity stain of glyoxalase II; at $4{ }^{\circ} \mathrm{C}$, the activity was decreased by ca. $80 \%$ and at $-20{ }^{\circ} \mathrm{C}$ the activity was decreased by ca. $30 \%$ after 6 weeks of storage.

Glyoxalase II is a thioesterase (1). It is present in the cytosol of red blood cells as part of the glyoxalase system (3). Recent interest in the presence of glyoxalase II activity and isoforms in red blood cells of clinical blood samples has arisen from the correlation of characteristic activities of red blood cell glyoxalase II with the development of clinical complications associated with diabetes mellitus (14). It is not known whether this activity correlation is associated with different isoforms in complicated and uncomplicated diabetic patients, or whether it is due to other factors. A correlation with isoforms may be investigated by screening red blood cell glyoxalase II by a non-denaturing electrophoretic procedure. To screen diabetic patients for isoforms of glyoxalase II an improved polyacrylamide gel electrophoresis method was required.

Previously reported electrophoresis methods for the analysis of phenotypes of glyoxalase II used a starch gel procedure, e.g. (7). A polyacrylamide gel system is preferred because of the variability in quality of starch. We have described herein a cathodic continuous polyacrylamide gel electrophoresis procedure for analysis of glyoxalase II isoforms.

There is usually only one phenotype of glyoxalase II in human red blood cells $(7,8,15)$. However, two isoforms with isoelectric points of 8.09 and 8.40 are thought to be present (2). The use of anodic polyacrylamide gel electrophoresis to resolve these isoforms using buffers of $\mathrm{pH}$ values higher than 8.40, was excluded since glyoxalase II has poor activity stability in this $\mathrm{pH}$ range and the substrate $\mathrm{S}-D$ lactoylglutathione hydrolyses spontaneously at high $\mathrm{pH}$ (unpublished observation), thereby interfering with the staining procedure. Since human red blood cell glyoxalase II has good stability at $\mathrm{pH}$ values of $5-8$, a cathodic polyacrylamide gel electrophoresis procedure was developed. Uotila (2) has reported an acetate-buffered cathodic polyacrylamide gel electrophoresis procedure for analysis of human red blood cell glyoxalase II but obtained a large smear of activity stain overlapping into the haemoglobin band. This was reproducible in our hands. The method described here gave much better resolution, with sharper, discrete bands.

Staining for glyoxalase II activity is mediated by the formation of reduced glutathione. At the loci of glyoxalase II activity, S- $D$-lactoylglutathione is converted to reduced glutathione. This reduces 3-[4,5-dimethylthiazol-2-yl]-2,5-diphenyltetrazolium bromide, via the electron transfer mediator 2,6-dichlorophenol-indophenol, to produce the dark-blue/purple formazantype stain. No staining was obtained in the absence of S- $D$-lactoylglutathione or glyoxalase II activity, consistent with the specificity of the stained bands for glyoxalase II.

A reactive thiol could conceivably be formed by the action of $\gamma$-glutamyltransferase on S- $D$-lactoylglutathione (16). Although $\gamma$-glutamyltransferase is considered to be absent from red blood cells, it is thought to be present in plasma and other blood cells (17). Incubation of protein samples with the irreversible inhibitor of $\gamma$-glutamyltransferase acivicin (17) had no effect on the staining pattern, indicating that $\gamma$ glutamyltransferase activity did not significantly compromise the glyoxalase II activity stain.

The interpretation of the two bands of glyoxalase II activity is probably best described as indicative of two isoforms since, from previous reports $(7,8,15)$, we do not expect there to be two phenotypes in the blood samples of Caucasian origin studied, although unequivocal discrimination between isoforms and phenotypes of glyoxalase will be possible only when gene hybridisation probes become available. The presence of two isoforms is in keeping with the chromatofocussing results of Uotila (2). The electrophoretic mobility of isoforms in polyacrylamide gel electrophoresis is influenced by distinctive charge density, molecular shape and size characteristics of the proteins. The distinctive isoelectric points of the two isoforms partially resolved by chromatofocussing may be reflected in the two activity bands found in the polyacrylamide gel electrophoresis system described herein.

Isoelectric focussing of human red blood cell glyoxalase II has been performed by Uotila (2), but it produced many bands of activity stain. The lack of agreement between the chromatofocussing and isoelectric focussing results for glyoxalase II (similar discordant analysis is found for glyoxalase I) remains a matter of concern, but it may be due to artifactual binding of ampholines in isoelectric focussing (18).

The non-denaturing polyacrylamide gel electrophoresis method described is currently being used to in- 
vestigate the association of isoforms of glyoxalase II with diabetic complications. This electrophoretic method gave two activity bands in all donor blood samples studied to date $(\mathrm{n}=12)$.

\section{References}

1. Uotila, L. (1989) Glutathione Thiol Esterases. In: Glutathione: Chemical, Biochemical and Medical Aspects - Part A (Dolphin, D., Poulson, R. \& Avramovic, O., eds.) pp. 576-804, John Wiley \& Sons, New York.

2. Uotila, L. (1979) Glutathione Thiol Esterases of Human Red Blood Cells. Biochim. Biophys. Acta 580, 177-288.

3. Thornalley, P. J. (1980) The Glyoxalase System: New Developments Towards the Functional Characterisation of a Metabolic Pathway Fundamental to Biological Life. Biochem. J. 269, 1-11.

4. Honey, N. K. \& Shows, T. B. (1981) Assignment of the glyoxalase II gene (HAGH) to human chromosome 16 . Hum. Genet. 58, 358-361.

5. Mulley, J. C. \& Callen, D. F. (1986) New Regional Localisations for HAGH and PGP on Human Chromosome 16. Hum. Genet. 74, 423-424.

6. Mulley, J. C., Barton, N. \& Callen, D. F. (1990) Localisation of Human PGF and HAGH Genes to 16 p13.3. Cytogenet. Cell Genet. 53, 175-176.

7. Board, P. G. (1980) Genetic Polymorphism of Human Erythrocyte Glyoxalase II. Am. J. Hum. Genet. 32, 690694.

8. Sugita, H. \& Takahama, K. (1983) Red Cell Glyoxalase II Type in a Japanese Population. Jpn. J. Human. Genet. 28, $201-203$

9. Thornalley, P. J. (1991) Population Genetics of Human Glyoxalases. Heredity 67, 139-142.

10. Clelland, J. C. \& Thornalley, P. J. (1992) S-2-Hydroxylacylglutathione Derivatives. Enzymatic Synthesis, Purification and Characterisation. J. Chem. Soc. Perkin Trans. $\mathrm{I}$, in press.

\section{Acknowledgement}

A. C. M. thanks the Wellcome Trust for a Prize PhD studentship. This is a contribution from the Glyoxalase Research Group at the University of Essex in collaboration with Prof. P. H. Sönksen, St. Thomas's Hospital, London, U. K.

11. Leonici, G., Maresca, M., Balestrero, F., Armani, U. \& Piana, A. (1984) Platelet Glyoxalases in Thrombocytosis. Scand. J. Haematol. 33, 91-94.

12. Thornalley, P. J. \& Bellavite, P. (1987) Modification of the Glyoxalase System in Human Neutrophils During Functional Activation. Biochim. Biophys. Acta 931, 120-129.

13. Thornalley, P. J. (1988) Modification of the Red Blood Cell Glyoxalase System by Glucose in vitro. Biochem. J. 254, $751-755$.

14. Thornalley, P. J., Hooper, N. I., Florkowski, C., Jones, A. P., Lunec, J. \& Barnett, A. H. (1989) Modification of the Human Red Blood Cell Glyoxalase System in Diabetes Mellitus. Diabetes Res. Clin. Pract. 7, 115-120.

15. Charlesworth, D. (1972) Starch-gel Electrophoresis of Four Enzymes from Human Red Blood Cells: Glyceraldehyde3-phosphate Dehydrogenase, Fructoaldolase, Glyoxalase II and Sorbitol Dehydrogenase. Ann. Hum. Genet. 35, $477-$ 484.

16. Tate, S. S. (1975) Interaction of $\gamma$-Glutamyltranspeptidase with S-Acyl Derivatives of Glutathione. FEBS Lett. 54, $319-322$.

17. Meister, A., Tate, S. S. \& Griffiths, O. W. (1981) $\gamma$-Glutamyltranspeptidase. Methods in Enzymol. 77, 237-253.

18. Hare, D. L., Stimpson, D. I. \& Cann, J. R. (1978) Multiple Bands Produced by Interaction of a Single Macromolecule with Corner Ampholytes during Isoelectric Focussing. Arch. Biochem. Biophys. 187, 274-275.
P. J. Thornalley, $\mathrm{PhD}$
Department of Chemistry and Biological Chemistry
University of Essex, Wivenhoe Park
Colchester C04 3SQ, U. K. 